\title{
O PERFIL DO EGRESSO DO CURSO DE ENGENHARIA MECATRÔNICA DA UNIVERSIDADE FEDERAL DE SÃO JOÃO DEL- REI E SUA INSERÇÃO NO MERCADO DE TRABALHO
}

Anderson Ravikdos Santos - anderson.ravik@gmail.com

Cezar Massayoshi Vivas Sakuno - cezarvivas@yahoo.com.br

Victor Brenerda Silva Cruz - vitorbrener@hotmail.com

Rina Mariane Alves Dutra - rina@ufsj.edu.br

Universidade Federal de São João del-Rei - Campus Alto Paraopeba, Departamento das

Engenharias de Telecomunicações e Mecatrônica

Rodovia MG-443, km 7 - Fazenda do Cadete

36420-000 - Ouro Branco - Minas Gerais

Resumo: A análise da percepção dos egressos sobre o curso de graduação e o mercado de trabalho é uma importante estratégia institucional para verificar o desempenho e o entendimento situacional do curso de graduação. Pesquisas com esse objetivo favorecem a adequação da grade curricular, a gestão universitária e os processos de ensino e de aprendizagem. Dito isso, este trabalho apresenta um estudo qualitativo e descritivo sobre o perfil dos egressos do curso de Engenharia Mecatrônica da Universidade Federal de São João del-Rei e sua inserção no mercado de trabalho. Os egressos responderam um questionário eletrônico sobre informações demográficas, do curso, da continuidade aos estudos e do mercado de trabalho. Os resultados obtidos constituíram dados relevantes que poderão ser utilizados nas discussões de adequação do plano pedagógico e grade curricular às novas tecnologias e exigências do mercado de trabalho, tanto da Universidade Federal de São João del-Rei quanto de outras instituições. A pesquisa serve ainda de direcionamento para os atuais discentes do curso, sendo fonte de informações a respeito dos setores em que o Engenheiro Mecatrônico tem mais atuado, suas principais funções e faixa salarial, além de apontar quais têm sido os principais meios de ingresso no mercado de trabalho.

Palavras-chave: Pesquisa de Egressos. Engenharia Mecatrônica. Mercado de Trabalho.

\section{INTRODUÇÃO}

Inserir na sociedade diplomados aptos para o exercício profissional é um dos objetivos das universidades. Para tanto, elas devem ter o retorno quanto à qualidade desses profissionais que vem formando, principalmente no que diz respeito à qualificação para o trabalho (CES/CNE, 2019). Nesse sentido, é fundamental a integração entre a universidade e o mercado, onde destaca-se o egresso - aquele que efetivamente concluiu os estudos, recebeu o diploma e está apto a ingressar no mercado de trabalho - como fator de destaque e fonte de informação à Instituição de Ensino Superior (IES) que o formou (LOUSADA; MARTINS, 2005).

Para Brandalise (2012) e Andriola (2014) o feedback dos alunos formados é necessário para preposição da mudança curricular nos processos de ensino e de aprendizagem e na gestão universitária, além de constituir um canal de acompanhamento da trajetória acadêmica e de inserção no mercado de trabalho após a formatura. Desta forma, segundo Lima et al. (2019), a 
realização de pesquisas referentes ao levantamento de perfil profissional dos egressos é uma relevante estratégia institucional, pois servem como métricas de análise de desempenho e entendimento situacional. Sendo assim, o acompanhamento destes promove uma adequação às novas exigências do mercado de trabalho e da sociedade e, consequentemente, qualidade na formação dos futuros egressos (ANDRIOLA, 2014).

Face à importância dessa temática, o objetivo geral deste trabalho é avaliar o perfil do egresso do curso de Engenharia Mecatrônica da Universidade Federal de São João Del-Rei (UFSJ) e sua entrada no mercado de trabalho. Como objetivos específicos espera-se: (1) traçar o perfil dos egressos; (2) levantar parâmetros de influência na aceitação do egresso ao mercado de trabalho; (3) obter informações que possam ser utilizadas futuramente nas discussões de novo plano pedagógico e nova grade curricular, adequando-os às novas tecnologias e exigências do mercado de trabalho; (4) direcionar os atuais discentes do curso através de informações a respeito dos setores de atuação do engenheiro mecatrônico, suas principais funções e faixa salarial, além de apontar quais têm sido os principais meios de ingresso no mercado de trabalho.

\section{METODOLOGIA}

A pesquisa se deu por meio de uma análise qualitativa descritiva, a partir de um questionário exploratório de preenchimento anônimo, enviado à população de egressos formados do curso de Engenharia Mecatrônica da UFSJ. A lista com o nome e contatos de todos os egressos foi disponibilizada pela Secretaria Integrada de Coordenações de Curso do Campus Alto Paraopeba (SIGRA) sob aprovação do coordenador do curso. Segundo dados do Sistema de Controle Acadêmico da UFSJ (CONTAC), até abril de 2020 o curso contava com 233 alunos egressos formados. Vale destacar que o curso de Engenharia Mecatrônica, com duração de 10 semestres, teve suas atividades iniciadas em 2008, com uma entrada no início do ano, e, a partir de 2009, com uma entrada no início e uma no meio do ano. Em todas as entradas ingressaram 50 alunos.

O questionário, adaptado do estudo de Almeida et al. (2019) foi desenvolvido na plataforma gratuita Google Forms e conta com 69 questões divididas em três seções. A primeira, com o objetivo de levantar o perfil do egresso, refere-se a perguntas de aspectos demográficos. A segunda seção apresenta questões de avaliação dos aspectos gerais do curso, com o intuito de avaliar a influência das características do curso no mercado de trabalho. Para a maioria das questões desta seção foi utilizada a escala likert de avaliação, de 1 a 5 (PéssimoExcelente), permitindo verificar o nível de concordância do indivíduo com uma afirmação (VIEIRA; OHARA; DOMENICO, 2016). Por fim, a terceira e última seção conta com perguntas sobre a inserção do egresso no mercado de trabalho e interesse nos diversos tipos de pós-graduação, permitindo o mapeamento dos egressos no que se refere à qualificação e mercado de trabalho após a formação. O formulário ficou disponível entre os dias 19 de maio e 25 de junho de 2020.

O contato com os egressos foi feito inicialmente por meio de ligações telefônicas visando uma maior chance de os contatados aceitarem participar da pesquisa. Egressos que não atenderam os telefonemas foram contatados via e-mail e redes sociais. Em todos os casos o link do formulário foi enviado por Whatsapp ou e-mail, conforme prioridade do egresso.

Uma análise estatística foi aplicada através da plataforma Solvis para avaliar o grau de certeza de que o valor obtido de amostra representa a população. A plataforma online e gratuita disponibiliza uma calculadora a partir da qual é possível calcular a margem de erro de uma pesquisa inserindo os valores da população, tamanho da amostra e o nível de confiança desejado. 


\section{RESULTADOS E DISCUSSÃO}

Dos 233 egressos do curso de Engenharia Mecatrônica que compreendem a população da pesquisa obteve-se a participação de 144 (61,8\% dos egressos), no qual 22 egressos não foram contactados devido a informações de contato desatualizadas e 67 egressos optaram por não participar da pesquisa. Estabelecendo um nível de confiança de 95,0\% chegou-se a uma margem de erro de $5,1 \%$. Isso significa que há $95,0 \%$ de chance de os resultados dessa pesquisa representarem toda a população. Entretanto, as repostas da população podem variar $5,1 \%$ em relação às respostas obtidas com a amostra.

\subsection{Aspectos Demográficos dos Egressos}

A primeira seção da pesquisa permitiu levantar o perfil dos egressos. De acordo com os resultados, a maioria dos participantes é do sexo masculino $(86,1 \%)$ e possui entre 26 e 30 anos $(68,1 \%)$. Esses dados corroboram com a ideia de que engenharias pertencentes aos grupos III e IV tendem a ter baixa participação de mulheres, apesar de haver uma tendência de aumento ao longo dos últimos anos (BAHIA; LAUDARES, 2011; INEP, 2019). Além disso, a pequena média de idade pode se referir à recente implementação do curso, realizada em 2008. Em relação a modalidade do ensino médio, conforme Figura 1, a quantidade de egressos que cursaram totalmente em escola pública ou em particular é equiparada: $44,1 \%$ e $41,0 \%$, respectivamente. Esse fato aponta para uma eficiência do sistema de cotas promovido pela Lei 12.711/12, de 29 de agosto de 2012, que mesmo sendo implementado em 2012 já apresenta resultados (BRASIL, 2012).

Figura 1 - Modalidade de Ensino Médio cursada pelos egressos.

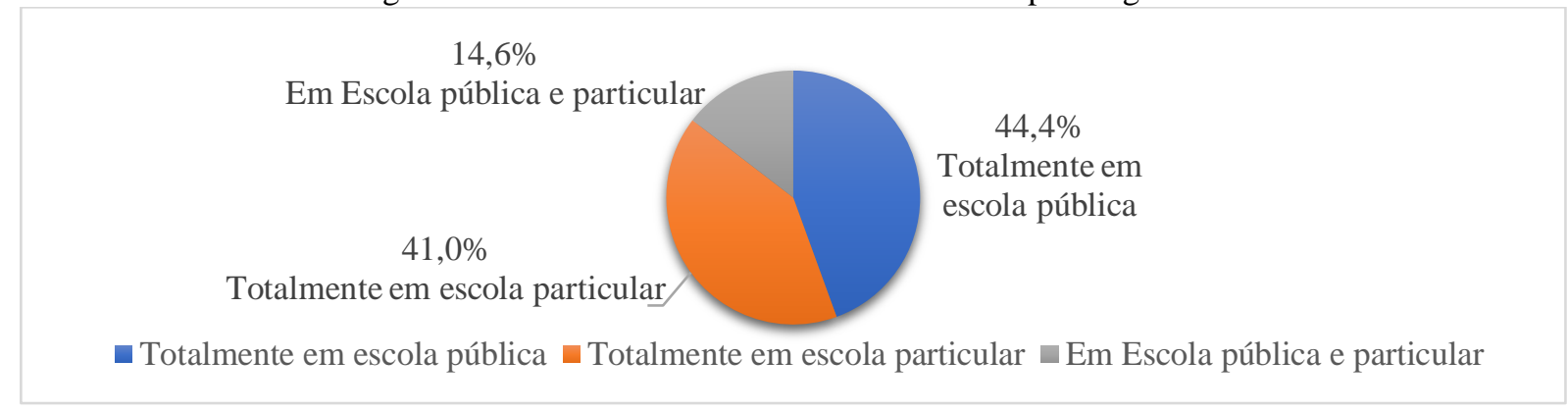

Fonte: Autoria própria

Quanto ao tempo que os egressos levaram para se formar, a média entre os participantes é de 12,8 semestres, ou seja, acima da média nacional de engenharia que é de aproximadamente 12,3 semestres (DALABONA; ALBERTI, 2016). Esse dado, acoplado a média nacional de evasão de 55,6\% na engenharia, justifica o baixo número de egressos do curso: eram esperados 700 egressos, porém apenas 233 já se formaram $(\mathrm{G} 1,2013)$.

No quesito escolha do curso, as principais razões apontadas pelos egressos foram afinidade com a área $(75,7 \%)$ e ampla possibilidade de atuação $(53,5 \%)$. Sobre essa questão, Hoernig e Felicetti (2016) e Silva e Silva (2017) enfatizam que os motivos se concentram na identificação com o curso, no aprimoramento profissional e no campo profissional-social com aberturas de portas no mercado de trabalho. Já a principal razão que levou a maior parte dos egressos a escolher o Campus Alto Paraopeba foi a localização (54,9\%), corroborando com o fato de que quase todos os egressos $(93,1 \%)$ residiam em Minas Gerais antes de ingressarem 
na Universidade. Os resultados estão coerentes com a média nacional no qual apenas $11 \%$ dos alunos se matriculam em um estado diferente da sua residência (INEP, 2019).

\subsection{Aspectos Gerais do Curso}

A segunda seção da pesquisa avaliou os aspectos gerais do curso, sendo que na maioria destas questões fez-se uso da escala de avaliação tipo likert. A Figura 2 mostra a avaliação da percepção dos egressos em relação a sua formação e preparação profissional.

Figura 2 - Avaliações realizadas na segunda seção do questionário.

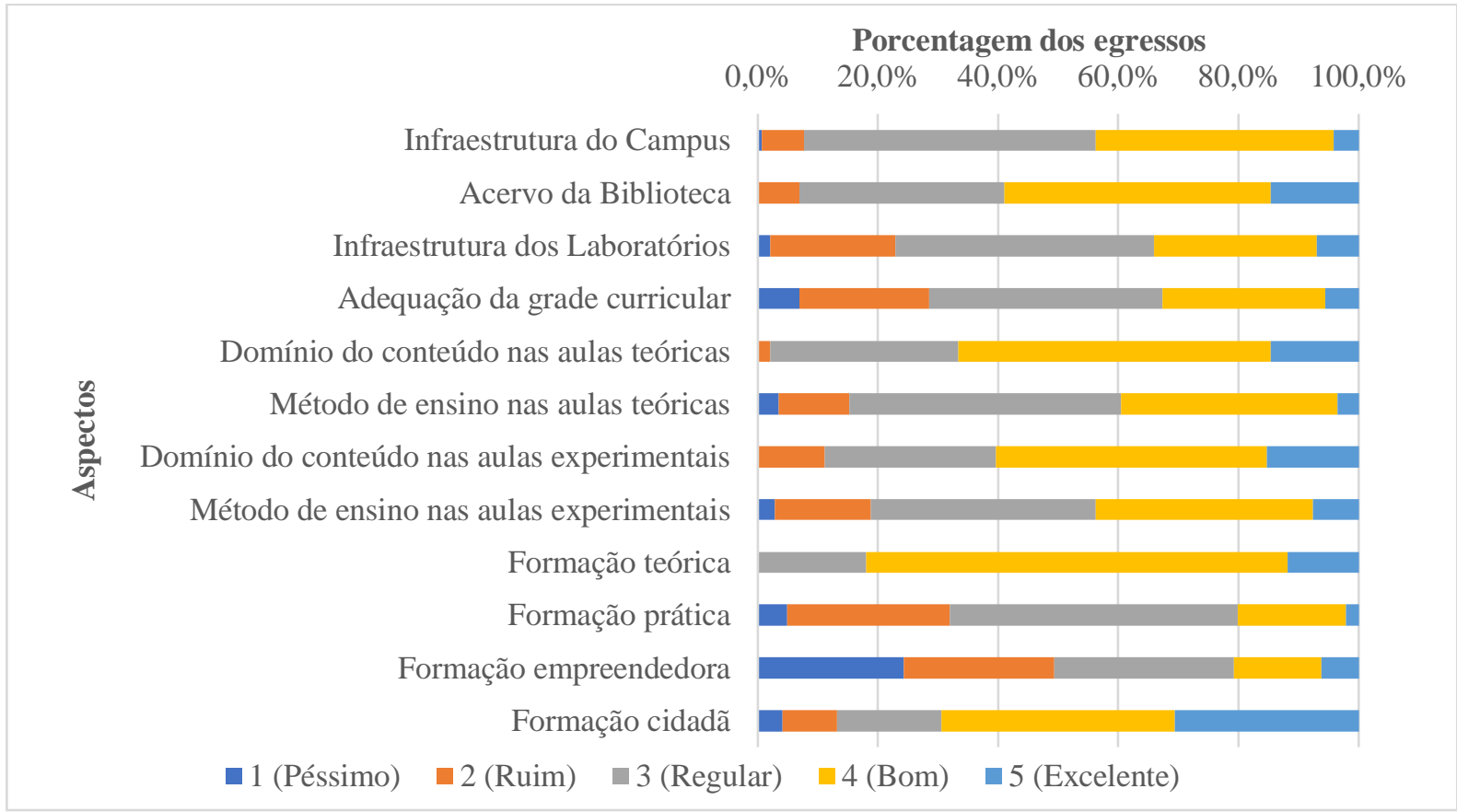

Fonte: Autoria própria

Os aspectos mais bem avaliados foram o acervo da biblioteca, o domínio do conteúdo nas aulas teóricas e experimentais e a formação teórica e cidadã, no qual pelo menos $50 \%$ dos egressos julgaram como Bom ou Excelente. Em contrapartida, os aspectos infraestrutura dos laboratórios, adequação da grade curricular, formação prática e, principalmente, formação empreendedora receberam a avaliação Péssimo ou Ruim de no mínimo $20 \%$ dos egressos.

Tem-se como necessidade então a melhora dos laboratórios e implementação de disciplinas práticas para promover melhor formação prática. Acredita-se que por ser um curso novo, muitos egressos não tiveram a oportunidade de estudar em laboratórios totalmente equipados. A hipótese é reforçada pela inauguração de laboratórios realizada em 2018, conforme noticiado em ASCOM (2018). Portanto, novas pesquisas devem ser implementadas para avaliar a percepção dos futuros egressos e avaliar se a nova infraestrutura é propícia para a formação de engenheiros mecatrônicos. Além disso, os resultados apontam para o desafio dos cursos de engenharia implementarem uma mentalidade empreendedora em seus alunos, bem como para a tendência do mercado em exigir esta formação (CANTO et al., 2017). De fato, não há registros de empresas encubadas na UFSJ provenientes de pesquisas desenvolvidas na área de mecatrônica. Por fim, os egressos destacam a indispensabilidade da adequação da grade curricular ao mercado, confirmando a relevância deste trabalho. Muitos 
citam, por exemplo, a inserção de disciplinas na área de mecânica e manutenção para melhor correspondência da grade ao mercado.

$\mathrm{Na}$ análise de satisfação com o curso, a maior parte dos egressos está muito ou extremamente satisfeita $(66,7 \%)$, conforme Figura 3. Ainda, 84,0\% dos egressos indicaria o curso para outras pessoas e $90,3 \%$ colaboraria num programa de parceria com UFSJ, o que corrobora com o nível de satisfação apresentado. Em vista disso, a satisfação corresponde aos dados da Figura 2, onde pode-se inferir, como indicado por Gouveia (2017), que o curso promove conhecimentos, habilidades e atitudes fundamentais ao exercício da engenharia.

Figura 3 - Nível de satisfação dos egressos com o curso.

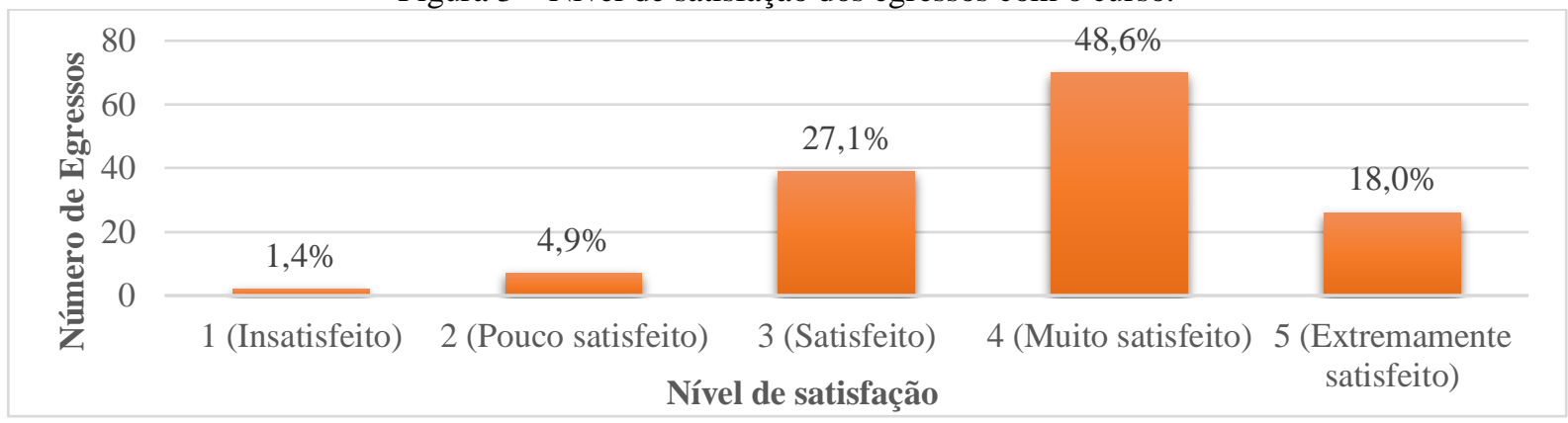

Fonte: Autoria própria

\subsection{Mercado de Trabalho e Pós-Graduação}

A terceira seção do formulário trata da inserção do egresso no mercado de trabalho e a continuidade da sua vida acadêmica. Quando perguntados sobre sua situação formal de trabalho, mais da metade dos egressos $(53,5 \%)$ disseram estar empregados na área de formação enquanto $31,2 \%$ estão empregados fora da área e $15,3 \%$ estão desempregados. Esses números são favoráveis à média nacional, no qual somente $42 \%$ dos engenheiros atuam na área, confirmando a demanda do mercado por engenharias voltadas para as áreas tecnológicas (MONACO, 2020). Ressalta-se que o índice de empregabilidade pode estar relacionado diretamente com o nível de satisfação do curso (Figura 3) visto que há alto índice de empregabilidade e satisfação. Além disso, dos 6,3\% dos egressos que apresentaram baixa satisfação (insatisfeito ou pouco satisfeito) a maioria está desempregada.

Quando a análise é referente ao sexo, posto que as mulheres são minoria no curso, há igualdade entre os gêneros na inserção no mercado de trabalho, sendo que $85,0 \%$ das mulheres e $85,0 \%$ dos homens estão empregados. O resultado contraria o estudo de Carneiro et al. (2019) que afirma que a escolaridade não garante a igualdade de gênero. Uma hipótese é que as mulheres, ao ingressarem na engenharia, apresentam melhor desempenho que os homens e, consequentemente, o maior desempenho reduz a desigualdade no mercado (SILVA; SILVA, 2017). Se a análise é referente à modalidade do ensino médio, pode-se afirmar também que este fator não é impactante na inserção no mercado de trabalho, uma vez que o índice de alunos que cursaram o ensino médio totalmente em escola pública ou totalmente em escola particular e que estão desempregados é o mesmo (aproximadamente 15,0\%). Uma possibilidade é que, conforme Pena, Matos e Coutrim (2020), o tipo de cota, que é dependente da modalidade de ensino médio, não interfere no rendimento acadêmico ao longo da graduação e, consequentemente, na inserção no mercado de trabalho. De um modo geral, infere-se que o desempenho ao longo do curso é um fator primordial para inserção ao mercado de trabalho. 
Em relação ao primeiro emprego, 36,1\% dos egressos já saíram do curso empregados e $34,1 \%$ conseguiram o primeiro emprego em até um ano. Ainda assim, $16 \%$ dos egressos demoraram de um a dois anos para trabalhar pela primeira vez. Dentre os desempregados, $61 \%$ tem menos de um ano de formado, ou seja, o desemprego pode estar relacionado ao tempo de adaptação e de conquista de uma vaga no mercado. Além disso, entre as dificuldades encontradas na entrada no mercado de trabalho, as que mais se destacaram foram a exigência de experiência $(66,0 \%)$ e os baixos salários $(36,8 \%)$, indicando deficiência na formação de engenheiros com elevada qualificação e a existência de vagas para engenheiro com funções de nível médio ou técnico (LGI, 2019).

Dos egressos que estão trabalhando atualmente, a maioria deles se concentra em empresas de grande $(43,1 \%)$ ou médio porte $(24,3 \%)$ atuando no setor Privado $(72,2 \%)$. Ou seja, os egressos contrariaram a média geral de engenheiros no setor industrial (54\%), reforçando a tendência de a Engenharia Mecatrônica estar relacionada às áreas de inovação e, como efeito, os engenheiros com esta formação atuarem no setor industrial (MONACO, 2014). Sobre os salários, $25,8 \%$ recebem mais que o teto salarial do profissional no estado onde o curso está implementado: $\mathrm{R} \$ 5.857,07$, sendo este um resultado satisfatório visto que 64,6\% dos egressos trabalham em Minas Gerais (SALÁRIOS, 2020). De um modo geral, $83 \%$ trabalham na região Sudeste e validam os dados de que engenheiros tendem a trabalhar nesta região (MONACO, 2014). Por fim, o número de egressos trabalhando no exterior $(6,3 \%)$ indica uma fuga dos engenheiros e, à vista disso, a carência brasileira de investir e incentivar indústrias com tecnologias de ponta.

No que diz respeito à continuidade dos estudos, 47,9\% está cursando ou concluiu pelo menos uma pós-graduação e apenas $6,3 \%$ não apresentam interesse em continuar os estudos. Por modalidade, $36,8 \%$ dos egressos concluíram ou estão cursando lato sensu enquanto que, na stricto sensu, esse número cai para $16,7 \%$. Tais características indicam uma amostra especializada (com ao menos uma pós graduação) já que somente $33,0 \%$ da população brasileira com ensino superior concluiu alguma especialização e $0,84 \%$ conclui algum mestrado (AGÊNCIA BRASIL, 2019; GIORDAN, 2020). Além disso, ressalta-se que 19\% dos egressos que já fizeram ou estão fazendo pós-graduação stricto sensu optaram por faze-la devido à falta de emprego e não por aptidão. Dado relevante diante do fato de $75 \%$ dos egressos que fazem uma atividade stricto sensu estarem empregados.

Neste contexto pode-se inferir que a busca dos egressos por pós-graduação está associada aos seguintes fatores, conforme apontado por Lourencetti, Sacomano e Ganga (2017) e Agência Brasil (2019): a amostra apresenta uma média de idade baixa, indicando mais disposição para novos estudos; a recente inserção no mercado relaciona a pós-graduação à prestígio e, consequentemente, uma forma de obter rápida ascensão na carreira; as crises econômicas direcionam o profissional à pós-graduação para garantir um diferencial e aumentar as chances de colocação no mercado e, por fim, a parcela atuante no setor público associando graus elevados de formação a maiores salários.

Sobre o método de inserção no mercado de trabalho, a forma mais comum foi a seleção de currículo (41\%). Isso reforça a hipótese de que o bom desempenho durante a graduação favorece a entrada no mercado de trabalho. As demais formas como concurso público, efetivação de estágio, indicação de pessoas influentes e empreendimento próprio também foram elencadas, porém cada uma não chegou a $14 \%$ dos egressos. Esses dados corroboram com o resultado de que a maior parcela dos egressos se concentra no setor industrial, cuja forma de seleção é em geral através de processos seletivos e análise de currículo (G1, 2019).

A respeito das funções que os egressos têm desempenhado no mercado de trabalho, destaca-se que as funções de gestão/gerência e de projetos apresentam a mesma porcentagem: $32,5 \%$, enquanto que as funções técnica, de ensino e outras são, respectivamente, $22,3 \%$, 
$9,5 \%$ e $3,2 \%$. Ou seja, é baixo o número de engenheiros assumindo responsabilidades de campo, o que corrobora com a necessidade de melhoria na formação empreendedora apontada pelos egressos (Figura 2) dado que funções de gestão/gerência implicam em uma cultura empreendedora e inovadora (CANTO et al., 2017).

O resultado final sobre o nível de satisfação dos egressos com sua situação profissional, como disposto na Figura 4, foi positivo: a maior parcela $(39,8 \%)$ se avaliou muito satisfeita enquanto $25 \%$ se disseram satisfeitos e $21,5 \%$ extremamente satisfeitos. Os 13,8\% restantes se dividiram igualmente entre insatisfeitos e pouco satisfeitos. Ressalta-se que $80 \%$ dos egressos insatisfeitos não estão trabalhando, ou seja, sua insatisfação pode estar relacionada ao mercado de trabalho e não à formação profissional. Isso indica que, apesar de novo, a UFSJ está oferecendo um curso de Engenharia Mecatrônica com formação de qualidade e adequada ao mercado de trabalho nacional.

Figura 4 - Nível de satisfação dos egressos com sua situação profissional.

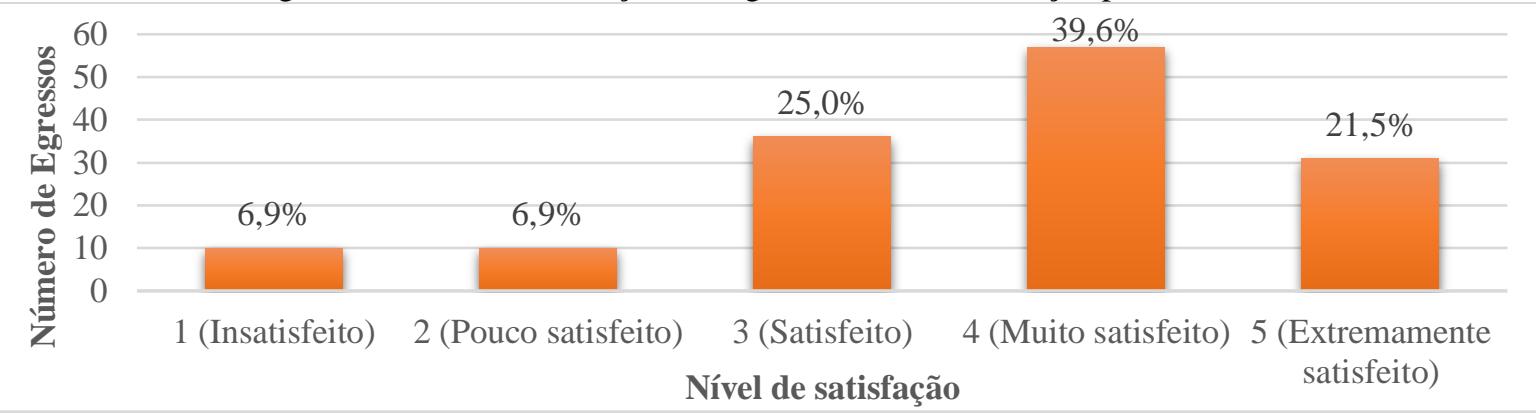

Fonte: Autoria própria

\section{CONSIDERAÇÕES FINAIS}

O presente trabalho se mostrou como uma eficiente ferramenta de avaliação do curso e principalmente da entrada dos egressos no mercado de trabalho, gerando um perfil dos egressos do curso de Engenharia Mecatrônica da Universidade Federal de São João del-Rei.

Pôde-se perceber que a maioria dos alunos formados está muito satisfeita com sua situação profissional e com o curso de Engenharia Mecatrônica. Ou seja, a universidade tem cumprido seu papel de formação e lançado profissionais preparados para a concorrência no mercado de trabalho. Ainda assim, há pontos que podem ser melhorados, como é o caso da formação prática e empreendedora dos alunos, que tem assumido consideravelmente funções de gestão. Não bastante, o estudo se mostra útil para o curso em uma futura adequação da grade curricular para atender aos requisitos das novas tecnologias e exigências do mercado de trabalho, que estão em constante mudança. Para os discentes que estão em curso, o trabalho aponta os setores em que o Engenheiro Mecatrônico formado no CAP tem mais atuado, suas funções, faixas salariais e quais têm sido os principais meios de ingresso no mercado. Informações estas que podem servir para nortear os alunos ainda durante a graduação.

Como limitação deste estudo, ressalta-se a ausência de análise por data de ingresso no curso e por tipo de currículo (Projeto Pedagógico do Curso), o que favoreceria uma comparação ao longo dos anos e, consequentemente, mostraria a tendência da qualidade e da adaptação ao mercado do curso de Engenharia Mecatrônica. Novas pesquisas devem ser realizadas visando coletar novos dados e compará-los aos já obtidos, traçando novas curvas de tendência. 


\section{REFERÊNCIAS}

AGÊNCIA BRASIL. Pesquisa revela crescimento de $\mathbf{7 4 \%}$ dos alunos de pós-graduação no país. 2019. Disponível em: https://educacao.uol.com.br/noticias/2019/12/06/pesquisarevela-crescimento-de-74-dos-alunos-de-pos-graduacao-no-pais.htm. Acesso em: 30 de julho de 2020.

ALMEIDA, P. H. C. et al. Pesquisa de acompanhamento dos egressos e avaliação do curso de Engenharia Civil da Universidade Federal De São João Del-Rei. 2019. 60 f. Trabalho de Conclusão de Curso (Bacharel Interdisciplinar em Ciência e Tecnologia) Universidade Federal De São João Del-Rei, Ouro Branco, 2019.

ANDRIOLA, Wagner B.; Estudo de egressos de cursos de graduação: subsídios para a autoavaliação e o planejamento institucionais. Educar em Revista, Curitiba, v.30, n. 54, p. 203-219, 2014.

ASCOM - Assessoria de Comunicação Social da Universidade Federal de São João del-Rei. Inauguração de prédio marca dez anos do curso de Engenharia Mecatrônica na UFSJ. 2018. Disponível em: https://www.ufsj.edu.br/noticias ler.php?codigo noticia=6862. Acesso em: 25 de julho de 2020.

BAHIA, Mônica M.; LAUDARES, João B. A participação da mulher em áreas específicas da engenharia. In: XXXIX Congresso Brasileiro de Educação em Engenharia, 2011, Blumenau. Anais. Blumenau, 2011.

BRANDALISE, Mary A. T.; Avaliação dos Cursos De Graduação na perspectiva dos egressos: um indicador de avalição institucional. IX ANPED SUL Seminário de pesquisa em educação na região sul, 2012, Caxias do Sul. Anais. Caxias do sul, 2012.

BRASIL. Lei $\mathrm{n}^{\circ}$ 12.711, de 29 de agosto de 2012. Dispõe sobre o ingresso nas universidades federais e nas instituições federais de ensino técnico de nível médio e dá outras providências. Diário Oficial da União: seção 1, Brasília, DF, ano CXLIX, n. 169, p. 1, 30 ago. 2012.

CANTO Filho, Alberto B. et al. Educação empreendedora em engenharia: situação atual e perspectivas no contexto brasileiro. In: TONINI, Adriana M. (org.). Desafios da educação em engenharia: formação acadêmica e atuação profissional, práticas pedagógicas e laboratórios remotos. Brasília: ABENGE, 2017. 189 p.

CARNEIRO, Sara G. et al. Mulheres nas ciências de exatas, engenharia e computação: uma revisão integrativa. Humanidades \& Tecnologia em Revista. Paracatu, ano XIV, v. 20, p. 159-175, 2019.

CES/CNE - Câmara de Educação Superior do Conselho Nacional de Educação. Resolução no 2 , de 24 de abril de 2019. Institui as diretrizes curriculares nacionais do curso de graduação em engenharia. Diário Oficial da União: seção 1, Brasília, DF, ano CLVII, n. 80, p. 43-44, 2019. 
DALLABONA, Carlos A.; ALBERTI, Mauro E. Evasão e retenção em cursos de engenharia: busca de respostas a partir de indicadores acadêmicos. In: XLIV Congresso Brasileiro de Educação em Engenharia, 2016, Natal. Anais. Natal, 2016.

GIORDAN, Isabela. 21\% dos brasileiros possuem Ensino Superior completo, aponta levantamento da OCDE. 2019. Disponível em: https://querobolsa.com.br/revista/21-dosbrasileiros-possuem-ensino-superior-completo-aponta-levantamento-da-ocde. Acesso em: 30 de julho de 2020.

GOUVEIA, Marco A. da C. Challenges for the future of engineering education. Revista Engenharia e Tecnologia Aplicada. Guarulhos, v. 1, n. 1, p. 4-23, 2017.

G1 - Portal da Globo. Só 44\% dos alunos de engenharia da última década terminaram o curso. 2013. Disponível em: http://g1.globo.com/educacao/noticia/2013/07/so-44-dos-alunosde-engenharia-da-ultima-decada-terminaram-o-curso.html. Acesso em: 25 de jul. de 2020.

G1 - Portal da Globo. 30\% dos recrutadores afirmam que eliminam currículo em até 10 segundos, diz pesquisa. 2019. Disponível em: https://g1.globo.com/economia/concursos-eemprego/noticia/2019/04/16/30percent-dos-recrutadores-afirmam-que-eliminam-curriculoem-ate-10-segundos-diz-pesquisa.ghtml. Acesso em: 28 de jul. de 2020.

HOERNIG Jr, Breno A.; FELICETTI, Vera L. Educação superior e a escolha do curso de engenharia. In: XII Semana Científica UNILAS ALLE, 2016, Canoas. Anais. Canoas, 2016.

INEP - Instituto Nacional de Estudos e Pesquisa Educacionais Anísio Teixeira. Censo da Educação Superior. Brasília, 19 de set. de 2019. Disponível em: http://portal.inep.gov.br/web/guest/sinopses-estatisticas-da-educacao-superior. Acesso em: 10 de jul. de 2020.

LGI - Laboratório de Gestão da Inovação da Universidade de São Paulo. Em três anos, número de engenheiros formados já supera em 2,5 vezes demanda prevista para 2020. São Paulo, 2019. Disponível em: https://sites.usp.br/lgi/em-tres-anos-numero-de-engenheirosformados-ja-supera-em-25-vezes-demanda-prevista-para-2020/. Acesso em: 10 de jul. de 2020.

LIMA, Ramon V. O. et al. Percepção dos egressos de engenharia de minas da Universidade Federal de Goiás - regional catalão em relação à gestão organizacional. Humanidades \& Tecnologia em Revista. Paracatu, ano XIII, v. 19, p. 212-228, 2019.

LOURENCETTI, Luiz A.; SACOMANO Neto, Mário; GANGA, Gilberto M. D. Identificação de valores relativos ao trabalho de alunos de cursos de pós-graduação de uma universidade pública. Perspectivas em Gestão \& Conhecimento, João Pessoa, v. 7, n. 1, p. 112-130, 2017.

LOUSADA, Ana C. Z.; MARTINS, Gilberto de A. Egressos como fonte de informação à gestão dos cursos de Ciências Contábeis. Revista Contabilidade \& Finanças, São Paulo, v. 16, n. 37, p. 73-84, 2005. 
MONACO, Rafael. Apenas $42 \%$ dos engenheiros brasileiros atuam na área em que se formam. 2020. Agência CNI de Notícias. Disponível em: https://noticias.portaldaindustria.com.br/noticias/inovacao-e-tecnologia/apenas-42-dosengenheiros-brasileiros-atuam-na-area-em-que-seformam/\#: :text=A\%20maioria\%20dos\%20engenheiros\%20brasileiros, Geografia\%20e\%20E stat\%C3\%ADstica\%20(IBGE). Acesso em: 15 de jun. 2020.

PENA, Mariza A. C.; MATOS, Daniel A. S.; COUTRIM, Rosa M. E. Percurso de estudantes cotistas: ingresso, permanência e oportunidades no ensino superior. Avaliação (Campinas), Sorocaba, v. 25, n. 1, p. 27-51, 2020.

SALÁRIOS. Engenheiro Mecatrônico - Salário 2020 e Mercado de Trabalho em Engenharia. Disponível em: https://www.salario.com.br/profissao/engenheiro-mecatronicocbo-202105/. Acesso em: 21 mai. 2020.

SILVA, Gabriel N.; SILVA, Sebastião C. B. Formação de engenheiros: um diagnóstico das condições dos estudantes de engenharia de três instituições públicas de ensino superior. Revista IGAPO. Manaus, v. 11, n. 2, p. 13-23, 2017.

VIEIRA, M. A.; OHARA, C. V. S; DOMENICO, E. B. L. The construction and validation of an instrument for the assessment of graduates of undergraduate nursing courses. Revista Latino-Americana de Enfermagem. Ribeirão Preto, v. 24, e2710, 2016.

Apresentadas em ordem alfabética e de acordo com a Norma ABNT - NBR 6023.

\title{
THE PROFILE OF GRADUATES OF THE MECHATRONICS ENGINEERING COURSE OF THE UNIVERSIDADE FEDERAL DE SÃO JOÃO DEL-REI AND ITS INSERTION IN THE LABOR MARKET
}

\begin{abstract}
The analysis of the graduates' perception about the undergraduate course and the labor market is an important institutional strategy to verify the performance and situational understanding of the undergraduate course. Research with this objective favors the adequacy of the curriculum, university management and teaching and learning processes. That being said, this paper presents a qualitative and descriptive study on the profile of graduates from the Mechatronic Engineering course at the Universidade Federal de São João del-Rei and their insertion in the labor market. The graduates answered an electronic questionnaire about demographic information, the course, the continuity of studies and the labor market. The results obtained constituted relevant data that can be used in the pedagogical plans and curriculum frameworks adjustments discussions to the new technologies and requirements of the labor market, both from the Universidade Federal de São João del-Rei and other institutions. The research also serves as a guide for the current students of the course, being a source of information about the sectors in which the Mechatronic Engineer has been most active, their main functions and salary range, in addition to pointing out which have been the main means of entry into the labor market.
\end{abstract}

Keywords: Graduates Research. Mechatronic Engineering. Labor Market. 